\title{
Redescubrir la dinámica escultórica desde el trabajo en grupo
}

\author{
Rediscover the dynamic sculptural since the group work
}

\author{
Antonio Vigo \\ Universidad Rey Juan Carlos \\ antonio.vigo@urjc.es
}

Recibido: 4 de marzo de 2015

Aprobado: 13 de diciembre de 2015

\begin{abstract}
Resumen
La iniciativa que se describe en este artículo, surge de una propuesta de investigación plástica, que se inició espontáneamente en el seno de una asignatura de escultura en la Facultad de Bellas Artes del CES Felipe II-UCM, y que tuvo como principal objetivo explorar nuevos modos de enseñanza artística desde la dinámica creativa en sí misma, con el fin de motivar el aprendizaje desde la participación directa en propuestas creativas que se apoyen en métodos de intervención crítica y que exploren las ventajas de las dinámicas interdisciplinares para complementar las eficacias de los ejercicios individuales, y así poder generar un aprendizaje desde dinámicas de trabajo en grupo. Para ello, hemos puesto en marcha procesos de trabajo cooperativo valorando sobre todo la experiencia directa, ofreciendo a los estudiantes contribuir en la actividad, tomar decisiones, lo que les permite aportar ideas, puntos de vista y opiniones sobre la combinación de nuevas tecnologías y técnicas tradicionales de la escultura, usados en proyectos artísticos actuales.
\end{abstract}

Palabras clave: trabajo grupal, universidad, artes plásticas, escultura, aprendizaje.

Vigo, A. (2016): Redescubrir la dinámica escultórica desde el trabajo en grupo. Arte, Individuo y Sociedad, 28(2) 297-309

\begin{abstract}
The initiative that described in this article comes from a plastic research proposal, which began spontaneously in the bosom of a course in sculpture at the Faculty of fine arts of the CES Felipe IIUCM, and whose main objective is to explore new modes of artistic education of creative dynamics itself, to motivate learning direct participation in artistic proposals that are based on methods of critical intervention and explore the benefits of interdisciplinary dynamics to complement the efficiencies of individual exercises, in order to generate a dynamic learning from working groups To do this, we have implemented processes of cooperative work valuing above all the direct experience, providing students contribute to the activity, make decisions, enabling them to contribute ideas, views and opinions about the combination of new technologies and traditional techniques of sculpture, used in current artistic projects.
\end{abstract} Keywords: working group university; visual arts; sculpture, learning. 
Sumario: 1. Construyendo al Monovidens, 2. El proyecto/fases de trabajo, 2.1 Orígenes del Monovidens, 2.2. Desplome/involución, 2.3. Levantar/adaptar, 2.4. Reconstrucción/evolución, 3. Conclusiones. Referencias.

\section{Construyendo el Monovidens}

En la actividad que se expone en este artículo, participó un considerable número de personas, entre los que aparecemos profesores de distintas disciplinas; ilustración, escultura, fotografía, y con la participación directa de alumnos de las distintas asignaturas que impartimos los profesores que formamos parte del proyecto.

El afán por establecer dinámicas de trabajo de este tipo en el proceso de enseñanzaaprendizaje se apoya en el hecho, que ya a nadie sorprende, que una buena parte del proceso artístico del siglo XX consistió en disolver los límites dogmáticamente establecidos entre los géneros o entre las disciplinas y que como resultado, ha dejado una huella en el quehacer artístico, propia de una época plural, abierta en el enfoque estético y en constante cambio. Este paradigma, hoy día está completamente aceptado y naturalizado, contribuyendo así a que las propuestas creativas sean más abiertas y ricas en matices. Este hecho, ha permitido que otras civilizaciones y culturas de mentalidades y experiencias diferentes puedan unirse para investigar sobre el arte en el presente milenio, que persigue ser internacional y universal y no acepta los límites. Por esta razón, la iniciativa de este trabajo de investigación plástica pretende apoyarse en la idea de que este principio rige muchos procesos creativos en la actualidad. De ello nace la decisión de buscar métodos de enseñanza en las artes plásticas que preparen a los alumnos de grado cuando finalicen sus estudios, para manejarse con éxito en la realidad presente del territorio artístico en general.

Dado que hoy día las teorías estéticas dan protagonismo a los nuevos procesos de producción y el consumo como paradigma más elevado, no es de extrañar que los artistas profesionales y quienes se forman en escuelas y centros universitarios de muchas partes del mundo, se encuentren fuertemente atraídos por un tornado de información de nuevas técnicas y materiales que se desarrollan a la misma velocidad que cambian las sociedades. El abanico amplísimo de procesos de creación artística se ha convertido en algo que preocupa a diseñadores, arquitectos y artistas, que hace mucho formaba parte de expertos y científicos. Esto ha supuesto que la alta tecnología, los productos especiales o interactivos están redefiniendo el entorno en el que nos hallamos y del que formamos parte. Podría decirse que toda técnica pertenece a su época, lleva escrito el nombre de su tiempo, pero también podríamos considerar en muchos casos que es la técnica la que forja a su época, la que la conforma y la define. Son los hallazgos técnicos los que trazan los caminos que recorre la historia de la humanidad. Como ejemplo significativo tenemos al grupo Factum Arte que tiene como leit motiv, la combinación entre las nuevas tecnologías y las destrezas artesanales en sus proyectos. Este es un equipo formado por artistas, conservadores y técnicos dedicados a la planificación y organización de proyectos de arte. Siendo así, un paradigma de la nueva configuración del funcionamiento del arte contemporáneo.

Desde esta visión surge la propuesta de investigación que se apoya en el modelo EEES, que destaca como característica primordial el aprendizaje individual y colectivo de los estudiantes y/o los docentes de la vida universitaria. Por esta razón 
los profesionales de la educación nos debemos hacer la siguiente pregunta; ¿cómo deberíamos enfocar nuestras actividades docentes para preparar mejor a nuestros alumnos?, como todos sabemos no hay una sola respuesta, pero hemos detectado algunos vacíos en la formación de los alumnos de nivel universitario, que residen en la carencia de ejercicios y propuestas en grupo en las facultades de bellas artes, españolas en particular.

En estos momentos, en los que los alumnos reclaman nuevos retos de diálogo, participación y compromiso, consideramos que la transversalidad debe ser un objetivo fundamental a tener en cuenta en nuestros programas formativos, fomentando el aprendizaje colaborativo.

La propuesta que presentamos, se originó espontáneamente, a partir de un trabajo realizado en el aula taller en el que se implicó un de estudiante de Bellas Artes, y se consideró, que construir una escultura que incorporase diferentes métodos de creación y que generase preguntas sobre los procesos creativos en sí mismos, podría suponer un aprendizaje relevante. La iniciativa propone abrir estrategias de aprendizaje basada en problemas y proyectos o de aprendizaje autodirigido, y experimentar lo que Carballo (2014) profesor de la UCM propone: Pasar de la reproducción memorística a la búsqueda y la investigación.

Así pues, se planteó como tema de trabajo, indagar en un modo de construcción espacio temporal que exponga un ámbito distinto de percepción. La combinación de un proceso de creación tradicional de la escultura con medios audiovisuales y con los de generación de formas tridimensionales con herramientas digitales, que pretenden dirigir nuestra atención hacia un entorno artificial que frecuentemente se nos pasa por alto, pero que cada día nos aleja más de nuestros verdaderos orígenes.

En este modo de entender el proceso escultórico, se hace especialmente relevante nombrar a Jaume Plensa, uno de los escultores que en su trayectoria artística manifiesta una evolución de formas a veces contradictorias, que nos revelan a un artista insatisfecho, en constante búsqueda de medios para expresarse. (Moure, 1989)

Poder transmitir a los alumnos que el uso de dos procesos distintos suponen dos maneras diferentes de pensar la escultura es uno de los objetivos que persigue esta investigación, apoyada en un planteamiento tal, como pensar que algunos propósitos tradicionales como por ejemplo, usar la piedra como materia escultórica no lo convierte en el fin fundamental de la escultura. No se trata de glorificar la acción de trabajar un material en particular como expone Plensa. Porque no es lo mismo usar la talla en piedra que la fundición, donde el escultor no tiene campo para intervenir durante el proceso de elaboración.

La talla en piedra, por el contrario, es un proceso en el que el escultor, mientras ejecuta la pieza, interviene, improvisa y puede modificar la obra, y de este modo banalizar la integridad de una idea muy trabajada. Al realizar las obras en la fundición, se protege la idea original de la destreza técnica del escultor, que puede ir en detrimento del resultado final. Apoyándonos en estos planteamientos, toma un interés especial la figura del Monovidens, que es una escultura que metafóricamente se construye así misma pero que necesita del grupo para ello. Ese grupo, al que nos referimos, podría aludir a cualquier comunidad, es símbolo del trabajo en equipo como en el proyecto: CREANDO AL MONOVIDENS, en el que participaron alum- 
nos, profesores y voluntarios del entorno de la universidad. Esta ambición en cuanto al modo de trabajar, resulta de lo que Moraza (2010, p.3) denomina:

Modos del deseo en la elaboración artística, el sujeto y toda la complejidad de sus vivencias forma una parte nuclear en la propia mesa de trabajo y en ese sentido es el juego más subjetivo que existe entre todas los trabajos humanos, pero también es el juego más social, donde uno está más expuesto a todo tipo de vínculos con el exterior, de opiniones, de exigencias y negociaciones externas, etc.

\section{El proyecto/fases de trabajo}

- Orígenes del Monovidens

- Desplome /involución

- Levantar/adaptar

- Reconstrucción/evolución

Estas fases del proceso son una en sí misma, aunque cada una de ellas tiene su momento y su lugar. Todas son una metáfora de la evolución de la especie humana, que completan una historia que transita entro lo real y lo onírico, la tecnología y la naturaleza, el humor y la tragedia de un relato narrado desde la experiencia directa del trabajo con los alumnos.

\subsection{Orígenes del Monovidens}

Los comienzos de esta propuesta creativa y formativa demuestran que no hay evolución sin conocer la dificultad y la adversidad, que el error puede convertirse en una estupenda oportunidad para el aprendizaje:

Este conocimiento experiencial, pragmático, insuficiente y con muchos errores, lo hemos ido construyendo en nuestra vida cotidiana, por lo que la función del aprendizaje relevante es, en buena medida, la de problematizar el mundo que nos rodea preguntándonos por su sentido y funcionamiento y utilizar el conocimiento científico a través de la investigación, el contraste, y la experimentación del cambio como la mejor herramienta de comprensión. Pérez, Soto, Sola \& Serván, (2009, p.9).

Esta idea coincide con la experiencia que nace del ejercicio de Enrique López Orduña, alumno de bellas artes que participó como becario durante el curso 20102011 de la asignatura de escultura donde desarrollamos esta investigación y que fue el origen de esta iniciativa. Enrique, en adelante "Quique" dijo que tenía mucho interés en realizar un modelado en arcilla de un mono de casi $1,90 \mathrm{~m}$ de altura. Y la respuesta que obtuvo fue una pregunta; ¿Tú sabes lo que supone eso? No le intimidó y tampoco se conformó con estudiar la anatomía del animal en bocetos y maquetas, y mucho menos modelarlo a escala como se le propuso, él quería construirlo, enfrentarse a un reto de esas características era su principal objetivo. Por supuesto se le avisó de las dificultades que entrañaba modelar una escultura de esas dimensiones y tipologías, pero finalmente la ilusión y el deseo de sus veintitantos años no le pudo a la razón. No fuimos capaces de apagar las ganas de Quique de hacer una escultura de estas dimensiones, y ya que es algo poco frecuente en los alumnos de bellas artes 
en estos momentos, en los que están más acostumbrados a los trabajos que den resultados rápidos, consideramos que sería una buena posibilidad para que sirviera de motivación al resto del grupo. Lo cierto es que todo lo que hemos experimentado con esta iniciativa no se hubiera conseguido si Quique se hubiese asustado cuando se le advirtió de las dificultades con las que se iba a encontrar. También el reto ha dado sus resultados, y si además, nos hubiéramos acomodado y no le hubiésemos permitido salirse de lo establecido en la programación de la asignatura no estaríamos presentando los resultados de la experiencia.

\subsection{Desplome/involución}

Como era de esperar, aunque parecía que la evolución del trabajo de Quique iba por buen camino, llegaron los problemas técnicos. El peso del barro con el que se modeló la figura no encontró la estructura que lo aguantara, y sin poder hacer nada, esta se desplomó y cayó al suelo. Ante los ojos incrédulos de Quique, allí estaba la escultura caída en el suelo del taller.

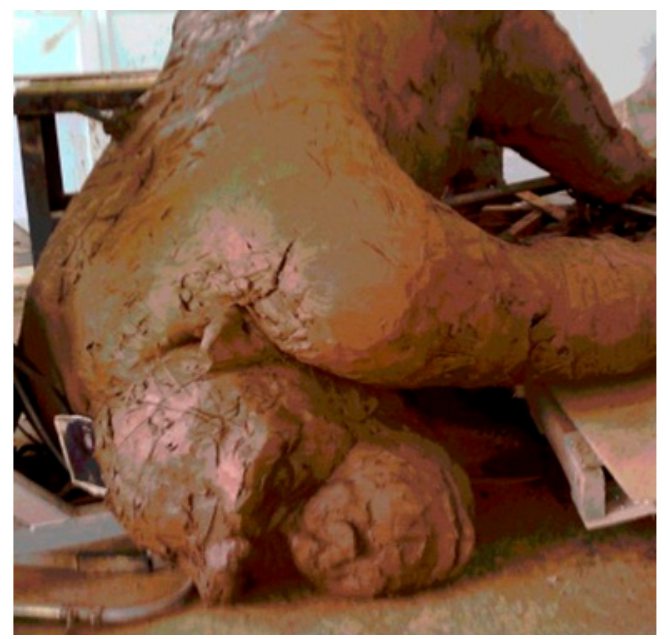

Figura 1. El derrumbe. Foto: Antonio Vigo.

Para estas situaciones, hay que hacer uso del tópico que sostiene la idea de que se aprende más de los errores, y lo cierto es que en este caso fue así. Quique en ese momento estaba conmocionado, había trabajado mucho para llegar hasta ahí pero su inexperiencia le llevó a no dar mucha importancia a la estructura de la escultura, y fundamentalmente, a no tener en cuenta lo necesario del trabajo de un equipo bien coordinado en iniciativas como esta. Lo cierto es que la imagen de la [fig.1] nos impulsó, pasado el trauma, a levantar la escultura y volver a empezar corrigiendo los problemas estructurales. Nos llenó de energía lo que (Moraza, 2009, p.7) expone:

Sin un fondo de asco, de miedo, de esperanza, de angustia, sin una vivencia de lo posible, de lo incompleto, sin un anhelo de cambio, de perfeccionamiento, sin la conciencia de lo problemático, resulta difícil la emergencia de una voluntad de solución, de un impulso de transformación, de un afán de obra. 
Desde este momento vimos una cadena de metáforas en el proceso de creación de la escultura y fue inevitable que comenzaran a generarse preguntas y respuestas de lo que estaba ocurriendo en el proceso de realización de la escultura. Lo significativo realmente fue, que este escenario comenzó a motivar a más alumnos a unirse al grupo e implicarse en la actividad.

\subsection{Levantar/adaptar}

Creímos sinceramente que Quique iba a abandonar su propósito, pero no fue así, volvió al trabajo con más ganas, y comenzó a pedir ayuda y buscar apoyos entre sus compañeros. Ese fue un momento decisivo para reunir a un grupo de voluntarios y decidir si merecía la pena organizar el trabajo para seguir adelante con la iniciativa.

Después de aceptar la propuesta comenzamos con las primeras reuniones de coordinación, y fue en ese momento donde se comenzó a definir lo que el profesor Carballo (2014) denomina - Pasar de la Jerarquía a la Democracia. Se replanteó el trabajo de la estructura y la base de madera para la escultura, también se aligeró el peso de la figura usando porexpán para dar volumen y modelar con barro encima, como tradicionalmente se solía hacer en trabajos de este tipo. Hoy día, los procesos técnicos han evolucionado en este sentido, y prácticamente no se trabaja así dicho sea de paso. En esta parte del trabajo la idea comienza a mutar, a evolucionar, y esto nos conduce al replantear el trabajo e investigar sobre el hecho de que el proceso plástico en muchos casos puede conducir a la idea y no al contrario.

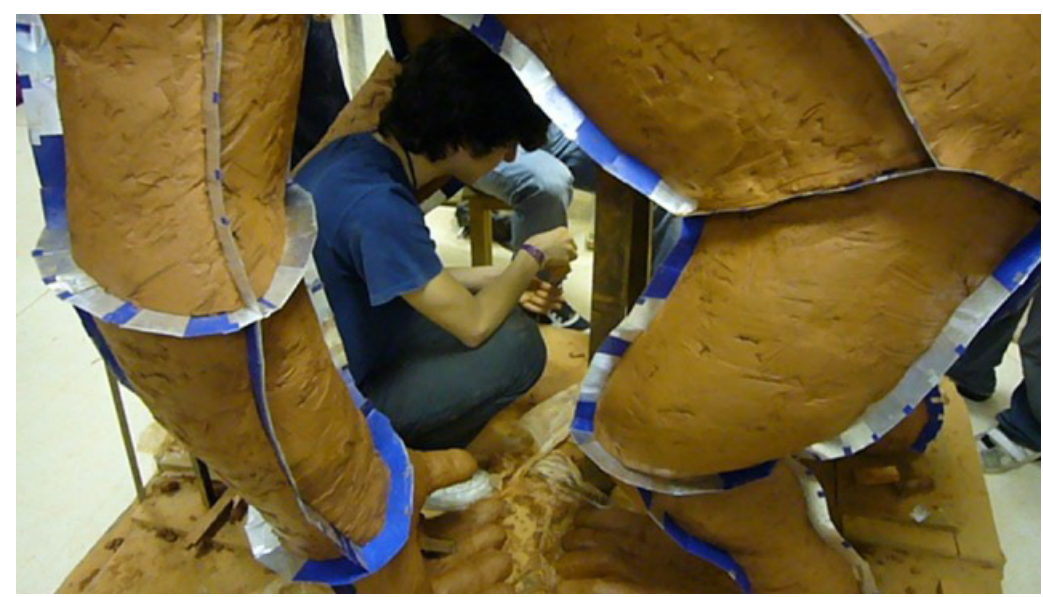

Figura 2. Alumnos realizando el molde de la figura, 2011. Fotografía: Antonio Vigo.

Una vez terminado el trabajo de modelado, la escultura comienza a tener sentido, y la idea avanza hacia un camino que no tiene mucho que ver con sus inicios, además la propuesta está cada día más viva y esto anima al grupo a implicarse en el proyecto. El concepto de como la escultura se reconstruye a si misma se plasmó en un video de animación, mediante la técnica "stop motion" usando la secuencia de fotos del trabajo de moldeado, para lo que un alumno se encargó de fotografiar en secuencias continuas del proceso para luego montarlo con un software de edición de video. 
Como en la obra de Gary Hill, queríamos contrastar el movimiento orgánico del cuerpo a través del video, opuesto a la inmovilidad estática del objeto escultórico. Esa interferencia en la percepción de la obra en la que parece que nada se corresponde, fue debatida después de una exposición en clase, en la que se mostró el trabajo de artistas que hacen uso de recursos tecnológicos, como son Bill Viola, Tony Ousler o Fabrizzio Plessi, quien presentó en el Simposio de Escultura de Alicante (SEA) la instalación L'Anima della Pietra (1993). Esta fue, del conjunto de esa exposición, la obra que más se asemejaba al trabajo que estábamos desarrollando en el grupo. La escultura de Plessi, se compone de módulos de metal sobre los que se encuentran doce monitores donde se reproducen imágenes de bustos tallados en piedra de la Catedral de Notre Damme de París, que se asemejan a negativos fotográficos y que recuerdan a las imágenes obtenidas por escáneres de los controles de seguridad, y doce piezas de mármol de Carrara en desbaste que recuerdan los trabajos inacabados de Miguel Ángel. Esta conexión en el modo de construir una escultura combinando una parte física-material y otra virtual-inmaterial nos emplazó en una postura definida y clara para avanzar en el proyecto.

\subsection{Reconstrucción/evolución}

En esta parte del proceso, hicimos una reproducción con fieltro de nuestra escultura. Nos interesó la idea de utilizar un material que aísla y retiene el calor, que conserva la energía que es signo de vida, de espíritu.

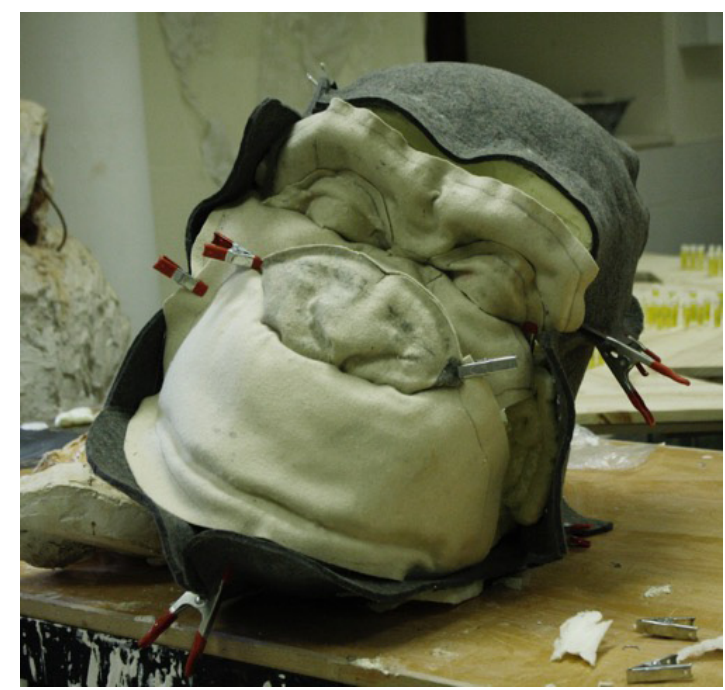

Figura 3. Reproducción de la figura en fieltro. Foto: Antonio Vigo.

Para ello utilizamos una técnica de reproducción sobre el molde de escayola al que posteriormente colocamos un esqueleto articulado que nos permitió mover "animar" la figura para la creación de un vídeo mediante la técnica de Stopmotion. Como lo hicieron creadores no muy conocidos por el gran público como Starewitch, Švankmajer y los hermanos Quay, cuya obra se presentó en La Casa Encendida 
(Madrid), bajo el nombre de la exposición METAMORFOSIS donde se muestra en profundidad el trabajo de los Estadounidenses hermanos Quay (1947) y del checo Jan Śvankmajer (1934) quienes están muy influidos por la obra del pionero del género, el ruso Ladislas Starewitch (1882-1965). Se propuso una visita a la exposición para contrastar las posibilidades que esta técnica podría ofrecer al proyecto, y si lugar a dudas, la experiencia que tuvimos durante la visita a la exposición METAMORFOSIS, abrió una reflexión en torno a la dualidad curiosidad/conocimiento y al papel de lo marginal en la creación contemporánea. Sin duda, este recurso nos resultó muy útil para satisfacer la necesidad, en la que coincidimos en todo momento, de contrastar la artificialidad del cuerpo que aparece en el video con el cuerpo real, realizado por procesos escultóricos tradicionales.

La técnica de stop motion ya que es un proceso de animación que consiste en aparentar el movimiento de objetos estáticos fotografiados previamente, nos permitió descubrir, como la realidad que nos rodea puede llenarse de vida y ser transmisora de continuas narraciones e historias repletas de contenido. Así, el mundo de la animación nos abrió las puertas de una gran vía de expresión artística y emocional, creando nuestro propio corto, nuestra historia, aquello que deseamos expresar con un lenguaje distinto.

Esta técnica nos resultó muy útil ya que se ajustaba perfectamente a la aventura de la desmaterialización del objeto como paradoja de nuestra realidad virtual. Obviamente, lo decimos aplicar desde su dimensión medial, y digamos que hicimos alusión a todos aquellos trabajos que enfocan su modo de distribución y experiencia pública a través de su presencia en algún mass media, en todo aquello que podemos denominar "media art". En definitiva aquellos trabajos cuyo modo de exhibición no se establece únicamente para ser mostrados en museos o en galerías, sino también a través de medios de comunicación incluido internet, y que contrasta plenamente con un proyecto escultórico, visto desde una postura más tradicional.

Consideramos bajo esta circunstancia, que la convergencia de la tradición conceptualista en movimientos como el media art, resulta del lógico desarrollo de la negación del objeto y la consecuente aportación del "documento" que hace posible su difusión, su comunicación pública. Así, este documento públicamente difundido y comunicado se convierte en el único signo restante de la "obra", y el único testimonio en última instancia de la práctica cultural desarrollada. De aquí surge la idea de acompañar a la escultura con su "documento", cargar con él, algo que resultó simpático a la vez que interesante para el grupo.

Este impresionante desplazamiento de superficies espacio-simbólicas de identidad se produce en numerosas obras artísticas que, abandonando los medios tradicionales de representación, hacen uso de la tecnología para significar una nueva construcción del cuerpo, de la identidad y del sujeto: nuevas formas de existir...de desear y de morir. Así, las instalaciones de video de Gary Hill en los años 90, tales como I Belive It is an Image in Light of the Orther (1991-92) o And Sat Down Beside Her, donde Hill propone estas zonas como "lugar de encuentro del cuerpo con la mente" y en las que plantea "el cuerpo en relación con la imagen y el significado". (Soláns, 1999, p.33). 
En una de nuestras reuniones de grupo, en la que se planteaba la necesidad de representar la escultura con un material ligero, que simbolizara el dinamismo evolutivo, se decidió usar un tejido cálido pero con un aspecto industrial para relacionar el avance tecnológico y la evolución, como se muestra en la [fig.5] de este artículo.
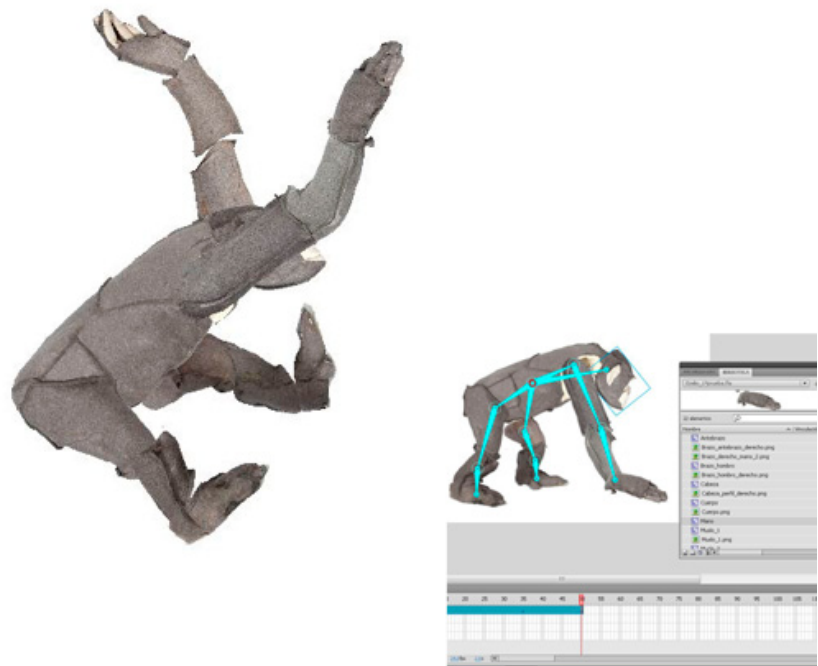

Figura 4. Animación Flash de la escultura, 2013. Captura de pantalla del proceso de animación 2d. Autor: Antonio Vigo.

Esté proceso también fue fotografiado íntegramente, fotograma a fotograma como se hizo en la realización del molde, para así simbolizar la evolución, el cambio de estado de la escultura que muta de un material a otro, como también lo hacen nuestros alumnos en cada etapa de su experiencia universitaria.

Para recrear virtualmente la escultura, usamos herramientas digitales de modelado y animación, que dieron como resultado imágenes que sirven como metáfora de los pensamientos y los sueños. Así, considerando lo que Soláns (1999, p.33) expone; "El modelo de identidad moderna que apuntaba a una construcción física del cuerpo, en la posmodernidad no hay cuerpos físicos sino transparencias, envolvencias, ausencias: ausencias que se resuelven en presencias simuladas. Cuerpo, pantalla e identidad en la estética posmoderna". Esta idea sirvió para representar el discurso interior que todos tenemos, como propuso un miembro del grupo, que vio en este desarrollo un ejemplo tan vinculado al de la performance, que inevitablemente lo relacionamos con las reflexiones de Rosalind Krauss sobre el carácter narcisista que marcó el nacimiento del vídeo arte:

¿Qué significaría decir "el medio del vídeo es el narcisismo"? Para empezar, esa afirmación tiende a crear una brecha entre la naturaleza del vídeo y la propia de las otras artes visuales; dado que tal aseveración describe una característica psicológica en lugar de una física y, por más que estemos acostumbrados a pensar en los estados mentales como un posible tema de las obras de arte, no se piensa en la psicología en tanto que elemento constituyente del medio.(Krauss, 2007, p.43). 
El uso de una herramienta de estas características fue motivada por la propia estética virtual (irreal) de los personajes generados con programas 3D y 2D que han servido para cubrir otra función; combinamos imágenes reales con virtuales que simbolizaron las ideas de un cuerpo-escultura que piensa y sueña.

La distancia metafísica entre representación y realidad (donde ella se estableciera justamente en el ostentar tiempos inversos, cruzados: lo real fluía y la imagen estatizaba, detenía el instante fugaz), esa distancia queda en esa obra, nuevamente, problematizada $-y$, por supuesto, si ello es posible es justamente gracias a la mediación de la técnica como productora de representación. Como ya he insistido, sólo el desarrollo de medios técnicos de captura y manipulación de la imagen ha permitido la germinación expansiva de un tiempo de la representación, de una representación temporalizada. (Brea, 2002, p.12).

Como ejemplo, observamos que el loop, material audiovisual que se reproduce en bucle al llegar a su fin, y que puede tener una repetición infinita, además de ser el bloque básico de construcción de un track [pista] de sonido electrónico, conquistó sorpresivamente una fuerte posición en la cultura visual contemporánea. Este elemento, las animaciones de Flash, las películas QuickTime, los personajes de los computer games se loopean infinitamente, hasta que el usuario interviene con un click. Todos los dispositivos visuales precinemáticos del siglo XIX también dependían del loop. A lo largo del siglo XIX estos loops fueron volviéndose más y más largos, transformarse casualmente en una narrativa (feature narrative). Hoy somos testigos del movimiento opuesto -los artistas samplean segmentos cortos de largometrajes o shows televisivos, disponiéndolos en loops y exhibiendo éstos como "video-instalaciones". El loop se convirtió así en el nuevo método por defecto [default] para "criticar" la cultura medial, reemplazando a la fotografía fija de la crítica posmoderna de los ' 80 .

Buscamos referencias en la obra de Bill Viola, que hace relación a la naturaleza atrapada de uno mismo y la presencia externa y un número considerable de fases existenciales, que giran en torno al yo. Al igual que Bill Viola, tratamos de plantear el problema de la identidad del sujeto como la disyuntiva divisoria que se produce entre nuestra vida interior y la exterior y del que el cuerpo es el escenario. Parece ser la tarea de Daniel Canogar con la que nosotros pretendimos de algún modo confluir, trabajar con las cosas y los cuerpos pero sin la realidad física de esos cuerpos y esas cosas, trabajar desde el territorio de las sensaciones corpóreas y desde la idea de percepción como se trabajaría con la piedra o con el lienzo. (Olivares, 1999).

\section{Conclusiones}

En un primer momento, la iniciativa que presentamos en este artículo, no tuvo buena aceptación por el grupo de alumnos, y consideramos simplemente que se debía a que este modo de aprender, les resultaba ajeno. Claramente los alumnos de bellas artes no están acostumbrados a trabajar en propuestas en grupo y por esa razón, y para que no se vieran forzados, se les pidió que participasen voluntariamente. Los que se animaron a colaborar vieron un enfoque real de esta práctica en el aula, y gradualmente se fueron familiarizando con el proyecto hasta sentirlo parte de ellos. 
Esta respuesta la consideramos como algo muy positivo ya que este fue uno de los principales objetivos de esta propuesta, observar el comportamiento de los alumnos ante trabajos que no sean solo ejercicios individuales en los que prime su desarrollo personal sin considerar el trabajo con el resto de compañeros.

Los alumnos que han participado en la experiencia que hemos desarrollado, han valorado positivamente el fenómeno de hacer confluir medios simultáneos, mezclando diversas técnicas como la escultura, la fotografía, la animación y el video. Ha sido enriquecedor experimentar la yuxtaposición de técnicas para ver varias realidades creativas al mismo tiempo, abriendo un campo inmenso a la interacción entre subjetividad y objetividad, al cruce entre el objeto y la mirada, y más aún; haciendo desaparecer los límites de la propia percepción del sujeto. Revisar esa necesidad de encuentro social, de apertura hacia el mundo, de salida del ensimismamiento individual y que es contraria al encuentro con el mundo real, es lo que hemos tratado de alcanzar con esta experiencia. Mostrar otra forma de ver la labor del artista, lo que declara cuando el escultor Moraza (2010, p.14) expone:

Todo deseo de vínculo aspira a una transformación. El encuentro con los otros destituye cualquier presuposición, cualquier ensimismamiento. El vínculo aspira a que la destitución subjetiva arranque una relación desde la que los sujetos se renuevan, dejan de ser lo que creen ser, quedan abiertos a convertirse, a devenir. Entiendo que ser artista es querer algo con los demás.

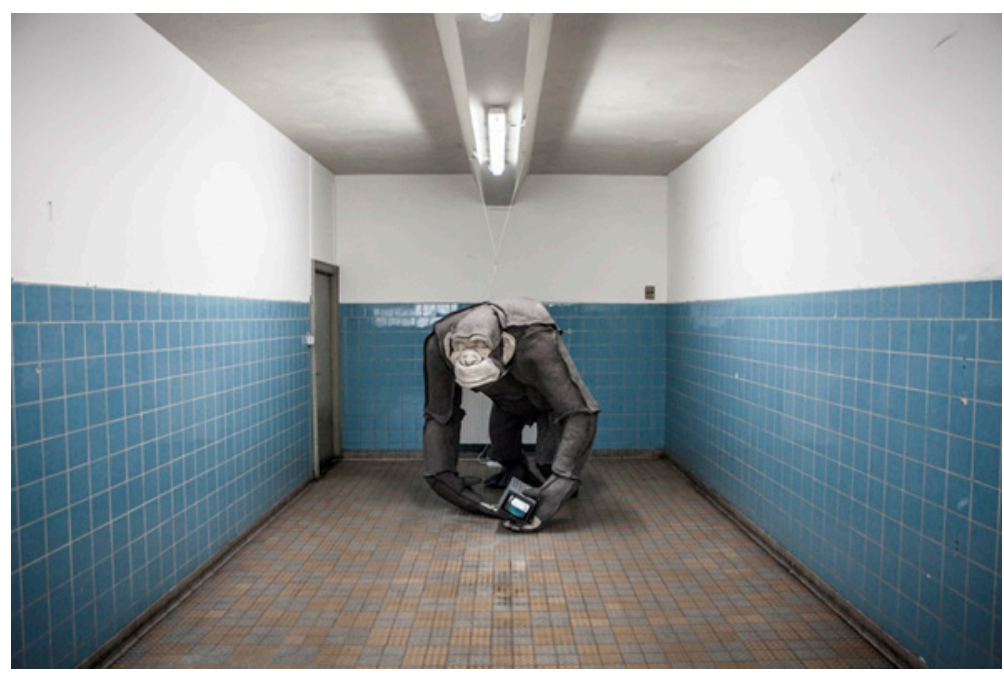

Figura 5. Resultado final de la obra. 2014. Foto. Miguel Sánchez-Moñita.

Hemos valorado que desde la participación activa en la que los estudiantes son protagonistas en la construcción del aprendizaje en las universidades, se obtienen resultados complementarios con los métodos que se amparan principalmente en las dinámicas individuales dirigidas y propuestas únicamente desde la visión de los docentes. Tal es el punto de satisfacción de los que impulsamos la propuesta que nos vemos en la necesidad de agradecer a todos los que han participado y apoyado esta 
actividad que fue expuesta en la Internacional Art Exibition NORDART 2015. El ver expuesto los resultados finales de la propuesta, supuso un reconocimiento al trabajo ya que pudimos valorar como nuestros debates y disertaciones tuvieron un resultado tangible y no solo se quedaron en meras especulaciones. Fue posible comprobar algo que nos interesó principalmente; la respuesta del espectador ante la obra. Pudimos comprobar como la reacción ante el objeto físico y el objeto virtual era muy diferente. Ante la realidad material el público se acercaba con asombro, por supuesto, rodeaban la pieza la observaban con una mirada más analítica. Por el contrario, la respuesta hacia el objeto virtual, era mas contemplativa produciendo la atracción habitual que toda pantalla ejerce sobre el observador. Estas razones hacen pensar, que experiencias colaborativas y de trabajo en grupo, deben tener una aplicación didáctica en la enseñanza superior del Arte, por su valor integrador de grupos de trabajo ya que son un complemento necesario al trabajo individual del alumno.

\section{Referencias}

Barkley, E.F, Cross, K. P. \& Howellmajor, C. (2007). Técnicas de aprendizaje colaborativo. Madrid.Traducido por Pablo Manzano: ed. Morata.

Brea, J.L. (2002). La era postmedia. Acción comunicativa, prácticas (post)artísticas $y$ dispositivos neomediales. Consorcio Salamanca.

Carballo, R. (2014,12 de noviembre). Pasar de la Jerarquía a la Democracia. Recuperado de http://www.robertocarballo.com/2014/11/12/hoy-empezamos-elv-encuentro/

Costa, J. (2014,22 de octubre). Museo imaginario del inconsciente. El País. Recuperado dehttp://cultura.elpais.com/cultura/2014/10/15/babelia/1413387114 615597.html

Herrero, M. R.\& García, M. A. (2013-2014). Equipos Docentes. Innovación docente en la universidad politécnica de Cartagena.

Recuperadode http://innovaciondocente.upct.es/publicaciones

Johnson, D. W., Johnson, R.T. \& Holubec, E.J. (1999). El aprendizaje cooperativo en el aula. Buenos Aires: Ed. Paidós.

López-Hernández, A. (2007). 14 Ideas clave. El trabajo en equipo del profesorado. Barcelona: Ed. Graó.

Moraza, J, L. (2009, abril) El deseo. Textos y conferencias. Ponencia dictada en el Colegio de Psicoanálisis del Campo Lacaniano, Madrid. Recuperado de http:// www.victordelrio.es/blog_docente/wp-content/uploads/2013/04/EL-DESEODEL-ARTISTA.pdf

Moure, G. (1989). Conversaciones con Jaume Plensa. Revista de arte Guadalimar $\mathrm{n}^{\circ} 101,20-25$.

Olivares, R. (1999). La tecnología es la prolongación de nuestro cuerpo. Lápiz (155), 49-51. Primera generación. (2006-2007).

Arte e imagen en movimiento 1963-1986. Madrid: Museo Nacional Centro de Arte Reina Sofía. 
Ors, J. (2013, 16 de febrero). Arco redescubre el taller de arte contemporáneo. La Razón. Cultura \&más. Recuperado de http://www.factum-arte.com/lib/kcfinder/ upload/files/articles/01.pdf

Pérez, Soto, Sola \& Serván, (2009). La Universidad del aprendizaje: Orientaciones para el estudiante. Madrid. Ed. Akal. Recuperado de https:/www.uco.es/ organizacion/eees/documentos/nuevastitulaciones/reforma/Plan_Bolonia.pdf

Poliestireno expandido (EPS) (2015). En Wikipedia. Recuperado de http:// es.wikipedia.org/wiki/Poliestireno_expandido (21 de febrero 2015)

Purbes, B. (2011). Stop-Motion. Barcelona: Ed. Blume.

Soláns, P. (1999). Lo sublime tecnológico. Lápiz (155), 33-36.

Universidad Politécnica de Cartagena, (2011). Equipo Docente de trabajo colaborativo. El aprendizaje colaborativo en la docencia universitaria: modelos en la UPCT. Cartagena. 